\title{
Pediatric deep brain stimulation: a cautionary approach
}

\section{Farah Focquaert*}

Department of Philosophy and Moral Sciences, Bioethics Institute Ghent, Ghent University, Ghent, Belgium

*Correspondence: farah.focquaert@ugent.be

Today, deep brain stimulation (DBS) is performed to treat dystonia in children as young as 7 years of age (Roubertie et al., 2000). For a variety of reasons, timely intervention in childhood dystonia is important: (1) to prevent irreversible damage, (2) to obtain optimal treatment outcomes, since severity and duration of the disease are negative prognostic factors for successful DBS treatment, and (3) to prevent longterm social costs due to social isolation (Isaias et al., 2008; Mehrkens et al., 2009; Clausen, 2010). Individual cases of DBS for neuropsychiatric disorders in adolescents have been published over the last 3 years (e.g., Shaded et al., 2007). Considering the investigational nature of DBS for psychiatric disorders, this is unsettling to say the least.

A group of experts recently proposed guidelines for the use of DBS for disorders of mood, behavior and thought (Rabins et al., 2009). Due to the investigational nature of DBS for psychiatric disorders, they defend the position that, at present, DBS for mood, behavior and thought disorders should be reserved for adults. However, they also put forward that "if DBS is found to be safe and effective for adults, then it might be appropriate to investigate its benefits for a younger population with severe, treatmentrefractory symptoms" (p. 933). Their opinion is quite different from the statement made by another group of experts on the use of DBS for Tourette syndrome (TS) in children (Mink et al., 2006). They argue that patients should be at least 25 years old, with rare potential exceptions involving younger patients. Bloch and Leckman (2009) similarly claim that "invasive interventions for TS such as DBS and neurosurgery are strongly discouraged until well into adulthood, even for patients with impairing tics" (p. 499).

Is it ethical to categorically exclude children and adolescent patients from receiving DBS for treatment-refractory disorders such as TS? If clear scientific criteria exist why specific pediatric disorders need to be excluded, then yes. However, if no such criteria exist for a given disorder, then surely it is unethical to categorically exclude children and adolescent patients from receiving the only treatment available that could dramatically increase their quality of life. Experts that oppose the use of DBS for pediatric TS (Mink et al., 2006; Porta et al., 2009) defend their position based upon the nature of childhood TS. According to a recent review, by early adulthood, approximately three quarters of children with TS will have greatly diminished tics and more than one-third will be tic free (Bloch and Leckman, 2009). A recent follow-up study on childhood and adolescent OCD found that $60 \%$ of children and adolescents did not have a full clinical disorder at followup, and two-thirds of participants rated themselves as much improved (Micali et al., 2010). According to the authors, many young people adapt to their illness and can lead a fairly normal life despite their symptoms. These are indeed important findings that highlight the exceptional caution that is needed when considering pediatric DBS for disorders that may spontaneously disappear or become subclinical over time. However, do they warrant the categorical exclusion of child patients? As Mink et al. (2006) themselves put forward: "Remission of tics may occur in the third decade of life in up to $50 \%$ of patients, but to date, there are no prognostic features that predict which patients will have a remission in their symptoms"(p.1832), and according to experts, the situation remains the same today. Which means that we do not possess clear scientific criteria to warrant the categorical exclusion of all child patients.

Children with severe treatmentrefractory diseases are an extremely vulnerable group, and they should not be exposed to an invasive intervention like DBS unless successful treatment outcomes have been established in adults. However, if treatment success for neurological or psychiatric disorders is established in adults, and provided no clear scientific criteria exist to categorically exclude minors, then children and adolescents can be involved in small-scale, early-phase studies provided these are done in research centers. Children with treatment-refractory disorders should not be categorically excluded from receiving DBS treatment, and this holds for any disorder for which treatment success has been established in adults and for which no clear scientific criteria exist that warrant their exclusion. Moreover, it is crucial that the decision-making process is a shared process between the child patient, the medical experts and the parents or parental guardians to maximally protect the vulnerable child patient. The decision-making process should involve a dual consent procedure with parents giving informed consent and children giving explicit assent. Medical experts should not start treatment in those cases where the only benefit to incur would be relief of caregiver burden. Unless clear scientific data can show that a child patient would benefit by receiving DBS treatment and would be harmed if not given treatment (e.g., cases of severe childhood dystonia), DBS treatment should not be performed if the child patient dissents. If successful, timely DBS treatment for dystonia benefits both the child patient (by preventing irreversible harm and long-term social costs due to social isolation, and providing optimal treatment outcomes) and the caregiver. Hence, we have strong reasons to consider DBS treatment in a timely fashion, and potentially even in those cases where the child patient dissents. This is not so for certain other disorders. If DBS treatment is performed for childhood TS or OCD that might have spontaneously remitted or become subclinical with time, then the dissenting child patient is harmed because an unnecessary invasive procedure was forced upon him/her, and the only benefit that occurred is a third-party benefit (i.e., caregiver relief). In fact, treatment compliance is a patient selection requirement according to the Italian DBS group treating TS (Porta et al., 2009). Indeed, it is crucial that the decision-making procedure is a shared process between child patients, medical experts and parents: (a) to ensure 
the best possible care and support during the treatment process, (b) to preserve family intimacy, and (c) to stimulate children's development of autonomy.

\section{REFERENCES}

Bloch, M. H., and Leckman, J. F. (2009). Clinical course of Tourette syndrome. J. Psychosom. Res. 67, 497-501.

Clausen, J. (2010). Ethical brain stimulation - neuroethics of deep brain stimulation in research and clinical practice. Eur. J. Neurosci. 32, 1152-1162.

Isaias, I. U., Alterman, R. L., and Tagliati, M. (2008). Outcome predictors of pallidal stimulation in patients with primary dystonia: the role of disease duration. Brain 131, 1895-1902.

Mehrkens, J. H., Boetzel, K., Steude, U., Zeitler, K., Schnitzler, A., Sturm, V., and Voges, J. (2009). Longterm efficacy and safety of chronic globus pallidus internus stimulation in different types of primary dystonia. Stereotact. Funct. Neurosurg. 87, 8-17.
Micali, N., Heyman, I., Perez, M., Hilton, K., Nakatani E., Turner, C., and Mataix-Cols, D. (2010). Long-term outcomes of obsessive compulsive disorder: followup of 142 children and adolescents. Br. J. Psychiatry 197, 128-134.

Mink, J. W., Walkup, J., Frey, K. A., Como, P., Cath, D., DeLong, M. R., Erenberg, G., Jankovic, J., Juncos, J., Leckman, J. F., Swerdlow, N., Visser-Vandewalle, V., Vitek, J. L., and the Tourette Syndrome Association, Inc. (2006). Patient selection and assessment recommendations for deep brain stimulation in Tourette syndrome. Mov. Disord 21, 1831-1838.

Porta, M., Servello, D., Sassi, M., Brambilla, A., Defendi, S., Priori, A., and Robertson, M. (2009). Issues related to deep brain stimulation for treatment-refractory Tourette's syndrome. Eur. Neurol. 62, 264-273.

Rabins, P., Appleby, B. S., Brandt, J., DeLong, M. R., Dunn, L. B., Gabriëls, L., Greenberg, B. D., Haber, S. N., Holtzheimer, P. E. III, Mari, Z., Mayberg, H. S., McCann, E., Mink, S. P., Rasmussen, S., Schlaepfer, T. E., Vawter, D. E., Vitek, J. L., Walkup, J., and Mathews, D. J. (2009). Scientific and ethical issues related to deep brain stimulation for disorders of mood, behavior, and thought. Arch. Gen. Psychiatry 66, 931-937.

Roubertie, A., Echenne, B., Cif, L., Vayssiere, N., Hemm, S., and Coubes, P. (2000). Treatment of early-onset dystonia: update and a new perspective. Childs Nerv. Syst. 16, 334-340.

Shaded, J., Poysky, C., Kenney, C., Simpson, R., and Jankovic, J. (2007). GPi deep brain stimulation for Tourette improves tics and psychiatric comorbidities. Neurology 68, 159-162.

Received: 03 January 2011; accepted: 18 April 2011; published online: 02 May 2011.

Citation: Focquaert F (2011) Pediatric deep brain stimulation: a cautionary approach. Front. Integr. Neurosci. 5:9. doi: 10.3389/fnint.2011.00009

Copyright $(02011$ Focquaert. This is an open-access article subject to a non-exclusive license between the authors and Frontiers Media SA, which permits use, distribution and reproduction in other forums, provided the original authors and source are credited and other Frontiers conditions are complied with. 